\title{
Mobilidade populacional, meio ambiente e uso da terra em áreas de fronteira: uma abordagem multiescalar*
}

\author{
Alisson Flávio Barbieri ${ }^{\star \star}$
}

\begin{abstract}
A mobilidade populacional tem sido historicamente um dos mais importantes determinantes próximos do desmatamento e da degradação de recursos naturais em áreas de fronteira. Abordagens analíticas "multiescalares" são particularmente apropriadas para compreender este tipo de relação entre mobilidade populacional, meio ambiente e uso da terra como sendo resultante da operação de fatores em diferentes, porém interconectados, escalas e níveis de análise espaciais e temporais. Entretanto, pouca pesquisa empírica tem sido feita na identificação simultânea de fatores em distintas escalas e níveis que afetam tal relação. Boa parte da literatura privilegia o estudo de dados agregados, dando menor atenção à análise micro (indivíduos e domicílios) e sua evolução no tempo. $O$ foco tem sido o impacto sobre as florestas tropicais, e não necessariamente as condições de vida e a mobilidade das famílias de migrantes que são diretamente responsáveis por grande parte desses impactos. Este artigo discute aspectos teóricos e metodológicos de uma abordagem multiescalar no estudo da relação entre mobilidade populacional, meio ambiente e uso da terra, além de apresentar um exemplo empírico em uma área de colonização agrícola na Amazônia equatoriana.
\end{abstract}

Palavras-chave: Mobilidade populacional. Meio ambiente. Uso da terra. Fronteira. Abordagem multiescalar.

\section{Introdução}

Embora a mobilidade populacional seja bastante significativa em seus efeitos sobre o desmatamento, a urbanização e o desenvolvimento regional, um número maior de estudos empíricos é necessário para clarificar importantes associações entre estratégias de subsistência rural - particularmente as que envolvem a mobilidade populacional -e estratégias de uso da terra que engendrem a depleção de recursos naturais em áreas tropicais de fronteira, particularmente na América Latina.
A escassez de evidências empíricas na literatura reflete, pelo menos em parte, a ineficácia das teorias existentes na identificação e análise de fatores-chave relacionados às causas e conseqüências da mobilidade populacional. Isso, por sua vez, reflete a complexidade teórica e fragmentação em estudos sobre a mobilidade populacional (ver discussão em BETTREL; HOLLIFIELD, 2000), bem como a dificuldade em se incorporar, em um único marco conceitual e estratégia analítica, a diversidade de escalas e níveis de análise afetando a mobilidade populacional. De fato, enquanto

\footnotetext{
* Uma versão preliminar deste artigo foi apresentada no XV Encontro Nacional de Estudos Populacionais, Abep, realizado em Caxambu - MG - Brasil, de 18 a 22 de setembro de 2006.

${ }^{\star *}$ Professor do Departamento de Demografia e pesquisador do Cedeplar, Universidade Federal de Minas Gerais.
} 
decisões sobre mobilidade populacional podem ser consideradas, em última instância, de caráter individual, a questão é como compreender a forma com que fatores associados ao grupo domiciliar ou familiar e à comunidade ou região ao qual o indivíduo pertence interagem com fatores individuais no processo decisório.

Este artigo discute aspectos teóricos e metodológicos de uma abordagem analítica multiescalar que reconheça a relação entre mobilidade populacional, meio ambiente e uso da terra como dependente da escala e como essencialmente dinâmica (variando à medida que as escalas temporal e espacial mudam). Inicialmente, são abordados aspectos empíricos em estudos sobre a associação entre mobilidade populacional, meio ambiente e uso da terra em áreas de fronteira, além das dificuldades inerentes para se definir uma análise multiescalar que contemple tal associação. Em seguida, são apresentados elementos de uma proposta de pesquisa multi-escalar que articule as dimensões espaciais e temporais da relação entre mobilidade populacional, meio ambiente e uso da terra. Discute-se, em seguida, um exemplo empírico de abordagem multiescalar em uma área de colonização na Amazônia equatoriana. O artigo encerra com algumas conclusões e implicações para políticas públicas.

\section{Aspectos empíricos em estudos sobre mobilidade populacional, ${ }^{1}$ meio ambiente e uso da terra em áreas de fronteira}

A fronteira pode ser definida, sob a ótica da dinâmica demográfica e em uma perspectiva multiescalar, como sendo configurada pelos fluxos populacionais iniciais (imigração e a "colonização pioneira") e subseqüentes gerações de colonos (isto é, os descendentes dos colonos pioneiros e os novos imigrantes). Tais fluxos são explicados tanto por fatores relacionados à dinâmica dos ciclos de vida pessoal e domiciliar e motivações ou aspirações pessoais quanto por uma diversidade de fatores contextuais, especialmente os relacionados à comunidade local, a mudanças estruturais no país, à agenda política (ou geopolítica) e à infraestrutura de transportes e comunicações. Estes fatores afetam a seletividade da mobilidade tanto da geração inicial quanto das gerações posteriores de colonos, bem como as percepções sobre oportunidades e limitações da mobilidade. ${ }^{2}$

A mobilidade populacional e a redistribuição da população têm sido fatores críticos para a expansão da fronteira agrícola e a conseqüente remoção da cobertura florestal nativa. Associado ao crescimento populacional via migração, as gerações subseqüentes de colonos atingirão, gradativamente, as idades adultas, constituindo um significativo "estoque populacional" que exerce pressão sobre a oferta de recursos naturais.

Paralelamente, grande parte dos solos tropicais, particularmente na Amazônia, tende a sofrer declínio em termos de qualidade e fertilidade, comprometendo, assim, a capacidade de sustento das famílias de colonos e engendrando mais mobilidade no tempo. As respostas mais comuns às limitações na oferta e qualidade de recursos são: adaptação dos sistemas agrícolas, envolvendo, em uma perspectiva boseupiana, a intensificação que visa tanto a subsistência como a produção de excedente para o mercado; a extensificação agrícola (incorporação de novas terras para cultivo agrícola), em uma perspectiva malthusiana; ${ }^{3}$ ou mesmo, de acordo com uma revisão da teoria de respostas multifásicas (BILSBORROW, 1987; BILSBORROW; CARR, 2001; BARBIERI; BILSBORROW

\footnotetext{
1 Por "mobilidade populacional" entende-se, neste artigo, processos de mobilidade espacial como a migração (mudança permanente de residência) e formas de mobilidade temporária, como as mobilidades sazonal e pendular. Uma definição mais ampla de mobilidade, não contemplada aqui, envolveria, por exemplo, processos de mobilidade social. 2 Para uma discussão mais aprofundada, ver Sawyer (1984).

${ }^{3}$ Cumpre observar aqui a influência da teoria de renda diferencial da terra, de David Ricardo, sobre o argumento de Malthus referente à possibilidade de migração para terras marginais (de fertilidade e produtividade menor, e conseqüentemente, gerando rendimentos decrescentes na perspectiva ricardiana).
} 
PAN, 2006), uma combinação dessas respostas com estratégias domiciliares de diversificação da renda via mobilidade populacional e, em última instância, regulação da fecundidade.

Dessa forma, uma conseqüência provável da busca por melhores condições de vida ou simplesmente pela sobrevivência, através da mobilidade, é a continuação do processo de mudança da paisagem na fronteira, aumentando tanto as taxas de desmatamento quanto a urbanização. ${ }^{4}$ Tem-se, assim, uma contínua expansão do "ciclo vicioso do desmatamento" (BARBIERI; CARR, 2005), que relativiza argumentos malthusianos segundo os quais o crescimento populacional é o único ou principal determinante da degradação ou depleção de recursos. De fato, um dos artigos mais debatidos sobre as causas próximas e subjacentes do desmatamento - a meta-análise envolvendo vários países do mundo - conclui o seguinte sobre o impacto de fatores demográficos sobre o desmatamento:

(...) entre fatores demográficos, somente a imigração de colonos para áreas de floresta esparsamente habitadas, com a conseqüência de aumentar a densidade populacional, apresenta uma notável influência sobre o desmatamento (...) isto tende a ocorrer mais na África e América Latina do que na Ásia. Contrariamente ao censo comum, o crescimento populacional devido a altas taxas de fecundidade não é um determinante primário do desmatamento na escala local em um período de tempo de poucas décadas (GEIST; LAMBIN, 2001, p.50, tradução nossa).

Por outro lado, mecanismos relacionados à mobilidade populacional que engendram modificações na paisagem devem estar articulados às estratégias e políticas de desenvolvimento e ocupação da fronteira, às condições nas regiões de origem que expulsam população para áreas de baixa densidade de ocupação e à atração exercida pelas áreas urbanas emergentes na fronteira. ${ }^{5}$ Assim, abordagens empíricas devem procurar articular o desmatamento tropical e a degradação de recursos às estratégias e características individuais e domiciliares e à percepção de mudanças nas oportunidades econômicas - as quais, por sua vez, estão articuladas a outras mudanças contextuais, de cunho social, político e de infra-estrutura.

Um outro aspecto importante da relação entre mobilidade, meio ambiente e uso da terra em áreas de fronteira é compreender a "causalidade inversa" ou "bi-direcionalidade", como os impactos do ambiente alterado sobre a saúde humana, particularmente o estabelecimento de níveis epidêmicos de doenças em áreas de ocupação, e como isto repercute na dinâmica dos fluxos populacionais (ver, por exemplo, BARBIERI, 2006; BARBIERI et al., 2005).

A compreensão dessas articulações esbarra em limitações apresentadas por estudos empíricos tradicionais sobre mobilidade populacional. A literatura tradicional sobre esta questão pode, grosso modo, ser dividida entre abordagens "micro" (focando indivíduos e domicílios) e "macro" ou "meso" (comunidades, municípios, regiões, países, etc.). Além disso, análises tradicionais sobre os determinantes da mobilidade populacional refletem vieses disciplinares (BILSBORROW et al., 1984; BETTREL; HOLLIFIELD, 2000; CASTLES; MILLER, 2003).

Bettrel e Hollifield (2000) mencionam, por exemplo, o viés da sociologia em privilegiar as conseqüências da migração, ou particularmente o processo de assimilação no destino, enquanto antropólogos têm preferido a análise qualitativa de aspectos sociais, culturais e de gênero que afetam decisões de mobilidade. Economistas têm privilegiado o capital humano e diferenças de renda e salário entre regiões como determinantes da mobilidade, negligenciado

\footnotetext{
${ }^{4}$ Obviamente, este processo associa-se a outros na explicação do desmatamento e da crescente urbanização da Amazônia, como, por exemplo, a expansão do capital agrário-exportador (como o cultivo de soja), do capital madeireiro e do capital especulativo. Ver, por exemplo, discussão em Browder e Godfrey (1997).

${ }^{5}$ Alguns exemplos seriam os mecanismos de expulsão (push) da população rural, das áreas de origem, em função da pobreza estrutural (decorrentes, entre outros fatores, da concentração de terra e de outros recursos produtivos) e fatores político-institucionais.
} 
dimensões sociais e culturais. Já os geógrafos têm enfatizado os aspectos espaciais da mobilidade, e não necessariamente quem move ou os motivos desse deslocamento (BILSBORROW et al., 1984).

Estudos sobre mobilidade populacional também refletem a carência de uma definição clara do significado de migração (como uma mudança permanente de residência) vis-à-vis outras formas de mobilidade temporária. Teorias de minimização de risco e diversificação de renda, por exemplo, tratam primariamente da mobilidade temporária, embora vários exemplos na literatura associem tais teorias a estratégias de mobilidade permanente (BARBIERI, 2006). Outra limitação em estudos tradicionais é a negligência da análise simultânea entre os fatores determinantes das decisões de mobilidade dos que efetivamente se movem e os daqueles que ficam, pois os determinantes e a conseqüências da mobilidade só podem ser adequadamente investigados em relação aos fatores que não geram tal deslocamento.

Uma implicação dessas limitações na literatura tem sido a falta de dados adequados e, até recentemente, de metodologias de análise multiescalares da mobilidade populacional e sua relação com fatores ambientais, o que dificulta capturar a natureza complexa dos determinantes da mobilidade populacional, que operam em escalas e níveis variados, e em especial sua inter-relação com fatores ambientais. Wood $(1982,2002)$, por exemplo, critica a carência de evidências empíricas e o excesso de explicações ad hoc na literatura, enquanto Stilwell e Congdon (1991) sugerem que a prevalência de abordagens disciplinares sobre a mobilidade populacional tem, a rigor, reforçado a dicotomia entre análises micro e macro. Massey (1990) também sugere que uma conseqüência da "fragmentação" de estudos sobre a mobilidade populacional em várias perspectivas teóricas e abordagens analíticas é:

[prevenir] analistas de reconhecerem relações fundamentais entre variáveis que afetam umas as outras através do tempo e entre níveis de análise, dependências essas que são intrínsecas à migração e que geram um forte momentum sobre o processo migratório (MASSEY, 1990, p. 4, tradução nossa).

Massey, seguindo diversos autores desde os anos 80 , conclui que um tratamento adequado dos processos migratórios deve incluir o desenvolvimento e teste de modelos multiníveis dinâmicos, que utilizem dados em distintas escalas e níveis temporais e espaciais. Tais modelos devem explicitar as dependências interníveis envolvidas nas decisões de mobilidade:

(...) decisões migratórias são feitas conjuntamente por membros da família dentro dos domicílios; decisões domiciliares são afetadas por condições socioeconômicas locais; as condições locais são, por sua vez, afetadas pela dinâmica das estruturas política, social e econômica nos níveis nacional e internacional; e estas interrelações são conectadas umas às outras no tempo (...) decisões individuais são inevitavelmente estruturadas pelos contextos social e econômico, os quais, por sua vez, refletem tendências e condições na economia política nacional e no próprio volume da migração (MASSEY, 1990, p.4-5, tradução nossa).

Em uma abordagem multiescalar, decisões individuais de mobilidade são afetadas pelo grau de acesso ou percepção das oportunidades oferecidas pelo contexto. Em particular, hipóteses de perfeita informação sobre lugares de origem e destino em áreas de fronteira são irrealistas a princípio, devido à existência de problemas estruturais (particularmente em áreas de fronteira), que criam ineficiências em redes de migração ou outros mecanismos pelos quais os ganhos potenciais da mobilidade são transmitidos. Além disso, abordagens atomísticas que privilegiam indivíduos como tomadores de decisões negligenciam estratégias coletivas, particularmente domiciliares e familiares, e as limitações impostas pela comunidade local (por exemplo, o sentido de comunidade, valores religiosos e familiares que restringem a mobilidade feminina, etc.).

O conceito de abordagem multiescalar nesse artigo refere-se à busca pela compreensão dos efeitos, sobre a relação entre mobilidade populacional, meio ambiente e uso da terra, dos múltiplos níveis de análise 
encontrados ao longo tanto de escalas espaciais (por exemplo, indivíduos, domicílios, comunidades, regiões) quanto temporais (anos, estações, etc.). A definição de tempo e espaço como dimensões da mobilidade populacional reflete uma discussão mais específica sobre a importância de se compreenderem as articulações entre níveis e escalas, em estudos envolvendo processos naturais e sociais (GIBSON et al., 2000; WOOD, 2002). Gibson et al. (2000, p. 291) definem escala como a dimensão espacial, temporal, quantitativa ou analítica usada para mensurar e estudar qualquer fenômeno, enquanto o conceito de nível pode designar uma região ao longo de qualquer escala de mensuração.

O termo abordagem multinível tem sido usado na literatura empírica, na maioria das vezes, para descrever regiões ao longo de escalas espaciais, havendo uma negligência quanto à importância do tempo como uma escala fundamental em estudos de determinantes da mobilidade (ver discussão em BARBIERI, 2006). A definição de uma dimensão temporal é particularmente importante, pois permite a busca e incorporação de fatores causais afetando a relação entre mobilidade populacional, meio ambiente $e$ uso da terra, que se estendem no tempo. É nesse sentido, por exemplo, que Blaikie e Brookfield (1987) discutem a importância de se incorporar uma escala temporal em estudos sobre população e degradação do solo como uma forma de compreender as implicações, em um dado período, de falhas no gerenciamento do uso do solo em períodos anteriores.

Em suma, sugestões de abordagens que considerem distintos níveis e escalas simultaneamente no estudo da mobilidade populacional não têm sido novidade na literatura (ver, por exemplo, MASSEY, 1990; BILSBORROW, 1987; BILSBORROW et al, 1984). Entretanto, pouca análise empírica tem sido feita neste sentido. Esta limitação é, em grande parte, resultante de vieses disciplinares e fragmentação de perspectivas teóricas existentes, da escassez de dados e pesquisas que contemplem múltiplas escalas e níveis e, até recentemente, da carência de metodologias adequadas que abordem a mobilidade populacional em uma perspectiva multiescalar.

\section{Elementos de uma abordagem multiescalar}

A unidade de análise privilegiada e sua articulação com níveis e escalas distintas

Uma das maiores dificuldades na elaboração de uma abordagem multiescalar é a definição das unidades de análise e suas articulações com diferentes níveis e escalas. Alguns autores (por exemplo, HARBISON, 1981; WOOD, 1982; BILSBORROW et al., 1984) sugerem que a unidade de análise mais apropriada em áreas de fronteira é o domicílio rural, ${ }^{6}$ devido à sua flexibilidade em acomodar e influenciar estratégias e comportamentos individuais, sintetizar e definir estratégias de ação coletiva e absorver e transmitir internamente aos seus membros as influências do contexto.

O domicílio pode constituir, também, uma arena de conflitos intergeracionais de gênero, que afetam decisões e propensões à mobilidade. Barbieri e Carr (2005), por exemplo, demonstram que a existência de importantes diferenciais de gênero entre migrantes na Amazônia equatoriana - com as mulheres mais jovens sendo mais propensas a migrarem para áreas urbanas próximas dos domicílios rurais dos pais - é explicada, em grande parte, pelas limitadas possibilidades de inserção laboral feminina em regiões rurais, pela preferência do trabalho feminino em áreas urbanas devido ao menor salário comparado aos homens e pela maior expectativa de que as mulheres enviarão remessas para o domicílio rural de origem, em função dos maiores laços com o domicílio de origem e aquiescência à autoridade paterna.

A rigor, uma mudança importante na literatura sobre mobilidade populacional foi

\footnotetext{
6 Por domicílio rural (ou simplesmente domicílio), entende-se aqui, e no restante desse artigo, o local de residência rural de um grupo familiar nuclear ou estendido, que inclui uma área utilizada para atividades agropecuárias ou extrativistas. Este significado é similar ao conceito de farm household, na língua inglesa.
} 
o deslocamento de perspectivas atomísticas e microeconômicas para uma abordagem em que o domicílio ou a família constitui uma unidade privilegiada de análise. Algumas perspectivas teóricas, como a Nova Economia da Migração do Trabalho (New Economics of Labor Migration - NELM; ver STARK, 1982), a "teoria de respostas multifásicas", na reformulação de Bilsborrow e colegas, a partir da proposta original de Davis (1963), e a "teoria de ciclos de vida domiciliares", inspirada nos escritos de Chayanov (ver THORNER et al., 1986) e aplicada à fronteira Amazônica por diversos autores (ver, por exemplo, WALKER; HOMMA, 1996; MARQUETTE, 1998; McCRACKEN et al., 2002; WALKER et al., 2002; BARBIERI et al., 2005; VANWEY et al., 2006), assumem a mobilidade como uma das estratégias domiciliares de minimização de risco e busca por determinado padrão de vida em áreas rurais.

Harbison (1981) também confere um papel central à família nas decisões de mobilidade, o qual é particularmente importante em sociedades em que a família representa uma unidade de subsistência e a estrutura por meio da qual o acesso aos recursos naturais é realizado:

[a família é o] contexto estrutural e funciona dentro do qual motivações e valores são moldados, o capital humano é acumulado, informação é recebida e interpretada [e decisões de mobilidade] são colocadas em operação (...) a natureza específica das relações entre o indivíduo, a família e o meio ambiente determina a direção de seus impactos sobre a decisão migratória. Em seu papel como unidade de subsistência, de socialização e de treinamento e de rede de comunicação e assistência, a família irá moldar as motivações de mobilidade de membros individuais (HARBISON, 1981, tradução nossa).

Além de seu papel como unidade de produção, a definição do domicílio como unidade de análise representa ainda a possibilidade de uma investigação mais adequada da relação entre dinâmica populacional e estrutura de consumo domiciliar, e conseqüentemente sua associação com estratégias de sobrevivência que envolvam a mobilidade populacional e o consumo de recursos naturais e energéticos. Tendo em vista que o consumo energético, sobretudo de lenha obtida da floresta nativa, apresenta uma associação direta com o tamanho médio do domicílio, o consumo de recursos energéticos e naturais tende a decrescer com o tamanho do domicílio, mesmo considerando que uma parte do consumo domiciliar é uma proporção fixa de recursos naturais.

Obviamente, o foco exclusivo no domicílio como unidade de análise privilegiada, sem a consideração de outros determinantes micro ou macro, representa a mesma armadilha de outras abordagens que não incluem a articulação entre múltiplos níveis e escalas. Assumir o domicílio ou família como a unidade de análise privilegiada não implica a negligência de indivíduos, comunidades, regiões, etc. como unidades articuladas de análise. Por exemplo, abordagens que tratam a dinâmica da relação entre ciclo de vida domiciliar e uso da terra de forma endógena não permitem verificar o grau de independência entre ambos, principalmente quando mediadas por efeitos de período (por exemplo, políticas públicas formuladas no nível nacional que repercutem na escala domiciliar e produção agrícola). Ao se considerar, também, que decisões individuais de mobilidade são condicionadas pelas características dos domicílios, é importante relaxar alguns dos pressupostos básicos da abordagem microeconômica - em particular, de que indivíduos são entidades autônomas para tomarem decisões sobre mobilidade a fim de maximizarem a renda, em um ambiente de perfeita informação sobre lugares de origem e destino.

É nesse sentido que Simon (1976) propõe a substituição do "indivíduo maximizador" e portador de conhecimento perfeito de todas as informações pertinentes para sua tomada de decisões, por um indivíduo que busca apenas escolher a primeira opção que aparece de forma satisfatória, entre todas aquelas disponíveis no curto prazo (em contraste à "escolha ótima" sugerida pela abordagem microeconômica). Dessa forma, o relaxamento do pressuposto de informação perfeita e independente abre a possibilidade de se reconhecer um ambi- 
ente de informação incompleta e distorcida na tomada de decisões de mobilidade, assim como a importância-chave do domicílio como elemento condicionador de estratégias individuais de mobilidade. ${ }^{7}$

\section{Definição de um marco conceitual multiescalar}

Um marco conceitual multiescalar da relação entre mobilidade populacional e meio ambiente reconheceria, como sugerido por Gibson et al. (2000), que variáveis explanatórias dessa relação mudam qualitativa e quantitativamente à medida que a escala de análise se altera, tanto espacialmente (domicílios rurais, comunidades, regiões, países, etc.) quanto temporalmente (semanas, meses, anos, ciclos, etc.). Fatores causais na relação devem ser entendidos como dependentes da escala e das interações entre escalas e níveis. A construção e operacionalização de um marco conceitual multiescalar requer, pois, a identificação de elementos (ou fatores, ou variáveis) que conectem seu nível e escala de análise correspondente a outros níveis e escalas. O propósito final seria, então, identificar uma "estrutura multiescalar" de incentivos e restrições à mobilidade ou à decisão de não se mover.

A definição apropriada da escala temporal é particularmente importante para capturar fatores que afetam as causas e conseqüências da mobilidade populacional (particularmente os fatores ambientais) em períodos passados. Isto remete a uma grande limitação na literatura empírica em boa parte das ciências sociais, conforme sugerido por Morgan (1993):

(...) a maioria das teorias [em ciências sociais] foca em padrões de mudança de longo prazo, mas a maioria das evidências empíricas vem de estudos do tipo cross sectional ou, na melhor das hipóteses, de períodos recentes (...) Dessa forma, estudos com horizontes temporais curtos são utilizados para testar teorias amplas sobre mudanças sociais, apesar de fatores idiossincráticos e temporais serem os responsáveis por boa parte das mudanças (MORGAN, 1993, p. 235-6, tradução nossa).
A avaliação temporal dos processos que afetam a associação entre mobilidade populacional, meio ambiente e uso da terra também requer a compreensão das interconexões entre fatores individuais, domiciliares e comunitários em um processo de causalidade cumulativa, no sentido proposto por Myrdal (1957). O argumento básico é de que a mobilidade populacional é um fator que, por si só, modifica as condições que engendram mais mobilidade ao longo do tempo. A migração pode, por exemplo, modificar a organização socioeconômica dos domicílios e comunidades rurais de origem, por meio: dos retornos ao trabalho e modificação dos padrões de consumo; de financiamento da produção através de remessas de migrantes ou poupança derivada da mobilidade temporária; e do incentivo ao uso de inovações tecnológicas e produtivas (por exemplo, uso de insumos químicos) que aumentem a renda agrícola.

Fatores relacionados ao ciclo de vida domiciliar que estimulam a seletividade da migração (por exemplo, a disponibilidade de indivíduos mais jovens e com melhor nível educacional) é outro mecanismo que pode reforçar o efeito de "causalidade cumulativa" ao longo do tempo (MASSEY, 1990; CURRAN, 2002). A interação entre seletividade e redes de migração ao longo do tempo, no entanto, pode tornar a primeira menos importante na definição de quem se move, devido, em grande parte, ao fato de a migração mudar, ao longo do tempo, as características da comunidade ou do contexto que influenciam a seletividade da migração. Por exemplo, a mudança do papel da mulher na divisão do trabalho, devido à introdução de novos valores em sociedades rurais, pode interagir com fatores individuais e domiciliares (educação, idade, etc.) para alterar a preferência masculina na mobilidade rural-rural e dessa forma equilibrar propensões de migrar entre gêneros (ver exemplo dessa discussão em CURRAN, 2002; BARBIERI; CARR, 2005).

\footnotetext{
${ }^{7}$ Este processo subótimo de escolha é chamado, por Simon, de satisficing - termo que combina as palavras inglesas satisfying (satisfazer) e sufficing (ser o suficiente).
} 


\section{Fontes de dados}

A elaboração de um marco conceitual multiescalar requer a disponibilidade de uma base de dados hierárquica e longitudinal (incluindo tanto dados de pesquisas amostrais quanto imagens de sensoriamento remoto ou uso de Sistemas de Informação Geográfico - SIG), que permita a mensuração da mobilidade e suas causas e conseqüências (particularmente as relacionadas a padrões ambientais e de uso da terra) em um determinado intervalo de tempo.

Pesquisas especializadas de migração são particularmente úteis em áreas de fronteira, sejam estas realizadas em conjunto ou separadamente de levantamentos sobre uso da terra, saúde, etc., pois permitem: a) capturar uma maior diversidade de movimentos populacionais vis-à-vis pesquisas generalistas ou censos demográficos; b) associar a mobilidade a fatores determinantes no momento exato ou aproximado da mobilidade; $c$ ) identificar conseqüências específicas da mobilidade para os domicílios e comunidades de origem e destino; e d) coletar informações sobre quem no domicílio influencia, de fato, a mobilidade de outros membros do domicílio.

Além disso, pesquisas que envolvem métodos apropriados de amostragem (superamostragem, estratificação e cluster, etc.) permitem lidar com o problema característico de migrante como "elemento raro", ou seja, de sua identificação na população. Ressalte-se ainda que uma pesquisa de migração deve coletar informações não apenas sobre os indivíduos do domicílio que se movem, mas também dos que não se movem - o que é particularmente importante para políticas públicas que visem aumentar o padrão de vida da população retida em áreas rurais.

Em uma abordagem multiescalar em áreas de fronteira, enquanto a associação entre indivíduos e domicílios é trivial nas etapas de elaboração do desenho amostral, coleta de dados e preparação da base de dados, a ligação de indivíduos e domicílios às comunidades rurais ou urbanas é mais problemática. Comunidades em áreas de fronteira podem variar enormemente em tamanho e características de infra-estrutura, serviços, homogeneidade cultural, etc., de- finindo, dessa forma, um contexto bastante heterogêneo para a tomada de decisões de mobilidade por indivíduos. Uma forma de associar domicílios rurais a comunidades é através da distância física (por exemplo, distância euclidiana) ou tempo de viagem - ou seja, a comunidade de referência de um domicílio rural será aquela para a qual a distância ou tempo de viagem for menor. Uma segunda forma de associação é a identificação da área de influência de uma comunidade sobre um domicílio rural, por meio de um conjunto específico de fatores ou variáveis (serviços como saúde, educação e cartório, atendimento religioso, mercado de trabalho e para a compra e venda de bens, etc.).

Por outro lado, pesquisas amostrais de migração, a não ser que estejam baseadas em amostras relativamente grandes, não são adequadas para estimar taxas (para tanto, censos nacionais constituem um instrumento adequado). O objetivo principal das pesquisas é explicativo, ou seja, coletar informações sobre os que se movem e os que não se movem e sobre o processo de mobilidade, em detalhes suficientes para possibilitar uma análise profunda dos determinantes e conseqüências da migração. Não obstante, o principal problema dos censos para a análise da mobilidade é justamente fornecer elementos para um estudo de causa e efeito entre mobilidade e seus determinantes e conseqüências (incluindo as ambientais), assim como estabelecer um período adequado de referência entre a mobilidade e seus fatores explicativos. Assim, pesquisas amostrais e censos podem ser vistos como instrumentos importantes, porém com finalidades distintas, e cujo uso conjunto pode ser útil para avaliar mais precisamente a importância dos movimentos migratórios, assim como servir de fonte de informação para políticas públicas.

\section{Operacionalização do marco conceitual multiescalar}

Nenhum modelo empírico, com sua simplificação da realidade, é capaz de representar plenamente a complexidade das relações existentes entre quaisquer 
fenômenos populacionais e naturais. Não obstante, a literatura empírica tem sugerido fatores em diversas escalas e níveis de análise, que afetam a relação entre população e meio ambiente (ver revisão da literatura em BARBIERI, 2006).

A operacionalização de um marco conceitual multiescalar envolve explicitar não apenas os efeitos independentes destes fatores em diversas escalas e níveis sobre a relação entre população, meio ambiente e uso da terra, mas também como diversos fatores se interconectam e interagem de forma a afetar tal relação.

São descritos aqui, brevemente, dois métodos multiescalares de análise da associação entre mobilidade populacional, meio ambiente e uso da terra: modelos estatísticos multiescalares e técnicas de análise espacial.

\section{Modelos estatísticos multiescalares}

A partir de uma base de dados hierárquica e longitudinal, pode-se construir uma variedade de modelos estatísticos multiescalares. Considera-se, a título de exemplo e por simplificação, um modelo incorporando somente a dimensão espacial, em que são definidos três níveis de análise: um indivíduo $i$ residindo em um domicílio rural $j$ em uma comunidade de referência $k$. Em um modelo multinível multinomial, as categorias da variável resposta podem ser descritas como $r$ : $r=1$, se o destino escolhido é urbano; $r=2$ se o destino escolhido é rural; e $s=r=0$, se o indivíduo opta por não se mover. Nessa situação, o modelo multinível multinomial pode ser descrito como:

$$
\begin{aligned}
& \log \left(\frac{\pi_{\mathrm{ijk}}^{r}}{\pi_{\mathrm{ijk}}^{s}}\right)=\gamma_{000}^{r}+\sum_{z=1}^{n}\left[\left(\gamma_{z}^{r} \mathrm{a}_{\mathrm{zijk}}^{r}+\gamma_{z}^{r} x_{z j k}^{r}+\gamma_{z}^{r} w_{z k}^{r}\right)+\right. \\
& \left.\left(u_{j k}^{r}+u_{0 k}^{r}\right) \mathrm{a}_{\mathrm{zijk}}^{r}+\left(u_{0 k}^{r}+u_{k}^{r} \mathrm{a}_{\mathrm{ijk}}^{r}\right) \mathrm{x}_{\mathrm{jk}}^{r}+\left(u_{0 j k}^{r}+u_{00 k}^{r}\right)\right] \\
& \text { em que og }\left(\frac{\pi_{\mathrm{ijk}}^{r}}{\pi_{\mathrm{ijk}}^{s}}\right) \quad \text { representa o log-odds }
\end{aligned}
$$

de se ter um evento do tipo $r$ ao invés de um do tipo s, a categoria de referência (decisão de não se mover). O termo $\gamma^{r} 000$ representa o intercepto do modelo; $\left(\gamma^{r}{ }_{z} a_{z i j k}+\gamma^{r}{ }_{z} x_{z j k}+\gamma^{r}{ }_{z} w_{z k}\right)$ representa:a) um vetor de $z$ variáveis independentes nos níveis individual (a), domiciliar (x) ou comunitário (w); b) um vetor $\gamma^{r}$ de uma variável independente, $z$, nos níveis individual, domiciliar e comunitário. Os termos u representam os efeitos aleatórios (random effects) de variáveis ou fatores não-observáveis operando nos níveis domiciliar e comunitário. Assume-se que os efeitos aleatórios são normalmente distribuídos $\left[\mathrm{u} \sim \mathrm{N}\left(0, \sigma_{\mathrm{u}}^{2}\right)\right]$. A fim de se observar a condição de independência de erros (visto que os termos de interação entre diferentes níveis violam o pressuposto de independência das observações), o modelo assume que, condicionado aos erros aleatórios $\mathrm{u}$, a variável resposta $\mathrm{Y}_{i j k}$ é independente.

A equação (1) representa um modelo de inclinações aleatórias (random slopes model), em que cada variável independente (ou um conjunto de variáveis independentes selecionadas) varia através de domicílios e comunidades. Isto é demonstrado pelo termo $\left(u_{j k}^{r}+u_{0 k}^{r}\right) \mathrm{a}_{\mathrm{zijk}}^{\mathrm{r}}+\left(u_{0 k}^{r}+u_{k}^{r} \mathrm{a}_{\mathrm{ijk}}^{\mathrm{r}}\right) \mathrm{x}_{\mathrm{jk}}^{\mathrm{r}}$. Este modelo permite verificar interações entre variáveis em diversos níveis: por exemplo, se o coeficiente (ou o efeito sobre a variável dependente) de uma variável independente qualquer, como idade, varia de domicílio para domicílio, ou alternadamente; se os coeficientes de uma variável domiciliar como tamanho populacional varia de comunidade para comunidade. Caso os termos aleatórios sejam restritos a zero - isto é, se $\left(u_{j k}^{r}+u_{0 k}^{r}\right) \mathrm{a}_{\mathrm{zijk}}^{\mathrm{r}}=\left(u_{0 k}^{r}+u_{k}^{r} \mathrm{a}_{\mathrm{ijk}}^{\mathrm{r}}\right) \mathrm{x}_{\mathrm{jk}}^{\mathrm{r}}=0$, tem-se um modelo de interceptos aleatórios (random intercepts model), em que a única variação entre domicílios e comunidades ocorre em seus interceptos, dados pelos termos $\left(u_{0 j k}^{r}+u_{00 k}^{r}\right)$.

Em suma, a grande vantagem do modelo descrito é a consideração da natureza hierárquica das variáveis explicativas - ou seja, leva em conta, na modelagem, o fato de que indivíduos dentro de um mesmo domicílio e domicílios dentro de uma mesma comunidade são mais homogêneos em termos de determinadas características ou variáveis (evitando-se, assim, a violação do pressuposto de independência de informações). A incorporação da dimensão temporal ao modelo descrito pela equação 
(1), caso estejam disponíveis informações longitudinais, ocorreria sem maiores dificuldades. Nesse caso, poder-se-ia considerar o "tempo" (por exemplo, medido em anos) um nível agrupado (clustered) em indivíduos (isto é, para um número $n$ de anos, cada indivíduo teria $n$ medidas de uma variável independente qualquer, por exemplo, variações de idade a cada ano).

\section{Análise espacial}

Outro importante componente metodológico de uma abordagem multiescalar é a identificação de como padrões espaciais (distância, densidade, distribuição espacial da população, distribuição espacial de recursos naturais como cobertura florestal, geomorfologia, hidrologia, etc.) ajudam a definir a estrutura de oportunidades e limitações que levam à mobilidade.

A análise espacial pode ser definida como uma análise quantitativa de dados, em que o foco é o papel do espaço e são utilizadas variáveis explicitamente espaciais na explicação ou predição do fenômeno sobre investigação (WEEKS, 2004). Trata-se, pois, de investigar como a locação em um ponto específico do espaço afeta a mobilidade, ou como a mobilidade afeta tais características locacionais (mormente as ambientais); e se esse efeito é aleatório na população ou é dependente de algum fator espacial específico. Análises de mudança na cobertura florestal e de uso da terra (LULCC) e o uso de Sistemas de Informação Geográfica (SIG) têm sido particularmente úteis para compreender como as características espaciais têm alterado a paisagem natural e socioeconômica.

Um dos aspectos mais importantes na análise espacial, particularmente no que se refere à análise da mobilidade populacional, é a autocorrelação espacial, que se fundamenta na primeira lei da geografia (também conhecida como Lei de Tobler): "Everything is related to everything else, but near places are more related than far places". Baseada na Lei de Tobler, a medida de autocorrelação espacial trata da semelhança da locação de objetos e seus atributos no espaço. Se os objetos espaciais são similares em sua lo- cação e atributos, configura-se uma situação de autocorrelação espacial positiva. Inversamente, autocorrelação espacial negativa ocorre quando objetos próximos são mais diferentes em seus atributos do que objetos mais distantes.

No geral, a autocorrelação espacial em modelos de migração pode levar a estimadores ineficientes. Por exemplo, domicílios vizinhos podem ser mais similares do que outros em determinados atributos (devido, entre outros, ao grau de parentesco ou por dividirem determinada infra-estrutura ou dotação de recursos naturais); essa homogeneidade, se não incorporada explicitamente no modelo estatístico, pode afetar pressupostos de independência de informações e, dessa forma, prejudicar a validade interna do modelo empírico e a inferência dos resultados do modelo.

\section{Sugestão de políticas públicas e a questão das falácias}

Uma análise multiescalar deve buscar sempre a identificação de elementos que informem adequadamente a elaboração de políticas públicas. A falta de uma análise mais apurada dos custos e benefícios, bem como dos determinantes e das conseqüências da mobilidade quando da formulação e implementação de políticas, pode agravar alguns problemas ou mesmo gerar benefícios não previstos. Por exemplo, a migração pode acentuar desigualdades regionais em países em desenvolvimento, levando a um êxodo rural massivo e explosão urbana (WOOD, 1982), o que é uma questão particularmente importante em áreas em processo incipiente de colonização e desenvolvimento. A intensa mobilidade rural-urbana, temporária ou permanente, está associada historicamente a vieses urbanos no favorecimento de políticas públicas em países em desenvolvimento, que podem inclusive, e contraditoriamente, anular outras políticas voltadas ao ambiente rural, que visem a intensificação agrícola como forma de retenção da força de trabalho. ${ }^{8}$

Alguns estudos também têm chegado a diferentes conclusões sobre os efeitos das

8 Ver Lipton (1977), para uma discussão sobre vieses urbanos em políticas públicas. 
políticas públicas direcionadas ao desenvolvimento rural e à mobilidade populacional (por exemplo, BILSBORROW et al., 1984; RHODA, 1983). Se, por um lado, o foco de ação política baseada em uma concepção de "desenvolvimento rural" pode apresentar um efeito importante e desejável sobre a melhoria das condições de vida locais, por outro, pode ter pouco efeito ou um efeito reverso se as decisões de migrar forem independentes dessa melhoria, por exemplo, devido a aspectos culturais que levam a mobilidade a ser uma espécie de "rito de passagem" (PIORE, 1979).

A rigor, a falta de consenso sobre os determinantes e conseqüências da mobilidade populacional reflete problemas usuais de inferências para políticas públicas e planejamento. Bilsborrow et al. (1984, p. 407), por exemplo, discutem problemas de "falácia ecológica" na formulação de políticas públicas que privilegiem o nível macro - ou seja, problemas de se inferirem relações causais a partir de relações observadas em níveis macro (ou de alta agregação), pelo fato de variáveis macro (ou agregadas) estarem altamente correlacionadas, o que torna a direção de causalidade ambígua. Também podem surgir problemas de "falácia individualista", ao serem inferidas relações sobre unidades agregadas (tais como comunidades), a partir do comportamento de indivíduos. A solução, de acordo com Bilsborrow et al. (1984), seria coletar dados e formular estratégias analíticas que contemplem, simultaneamente, os efeitos de características individuais, domiciliares e comunitárias sobre a relação entre população e meio ambiente.

Uma grande vantagem da abordagem multiescalar é isolar os efeitos de variáveis contextuais (comunidade, região, país, etc.), que afetam a associação entre mobilidade, meio ambiente e uso da terra, de fatores individuais e domiciliares. Esses "fatores macro" são os mais relevantes para a formulação de políticas públicas, sendo formuladas em escalas mais agregadas e "filtradas" para o nível micro e indicando o contexto ou a arena de decisões políticas em que decisões individuais e domiciliares são tomadas.

\section{Mobilidade populacional e uso da terra na Amazônia equatoriana}

Análises multiescalares na área em estudo

A Figura 1 demonstra a área de colonização em estudo na Amazônia equatoriana,

FIGURA 1

Área em estudo na Amazônia equatoriana

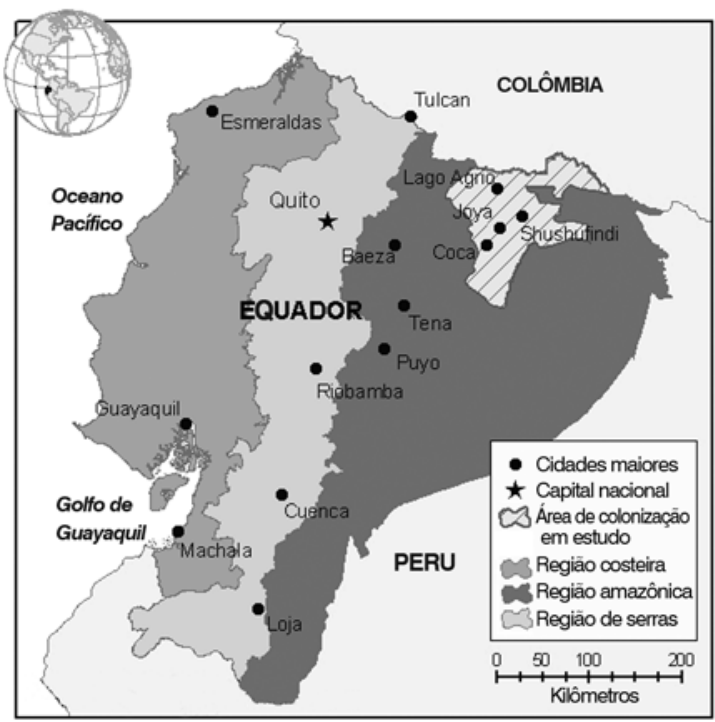

Fonte: Barbieri (2006). 
região também conhecida como "Oriente", que teve seu período inicial de colonização após a descoberta, em 1967, de reservas de petróleo economicamente viáveis. Isso levou à abertura de estradas pela indústria petroleira, o que, associado à concentração agrária das partes mais densamente populosas do país, constitui grande incentivo para a migração espontânea para a Amazônia, acarretando o processo de desmatamento na região. No Oriente, o fato de a fronteira ser "fechada" devido às limitadas possibilidades de extensificação (ao contrário da Amazônia brasileira), associado ao crescimento natural alto e à continuada imigração para a fronteira, também é um fator contribuinte para taxas elevadas de desmatamento (BILSBORROW et al., 2004).

Estudos recentes no Oriente têm realizado uma abordagem multiescalar na avaliação da relação entre a dinâmica populacional e o meio ambiente (ver, por exemplo, BARBIERI, 2006; BARBIERI; CARR, 2005; PAN; BILSBORROW, 2005; WALSH et al, 2003). Tais estudos têm utilizado dados longitudinais referentes ao período 1990-1999 e níveis de análise espacial, que incluem indivíduos, fazendas e domicílios rurais, fincas (aglomerado de domicílios rurais), comunidades rurais e províncias.

As Figuras 2 e 3 ilustram um exemplo de análise sobre padrões de desmatamento na área em estudo, conforme os níveis nas escalas espacial e temporal utilizadas (BARBIERI et al., 2003). A Figura 2 demonstra as taxas de desmatamento anuais (entre 1986 e 1996) estimadas por parroquia (unidades administrativas equivalentes, no caso brasileiro, aos municípios). As informações referemse à média do desmatamento em fincas (lotes rurais) localizadas na área da parroquia correspondente, o que limita inferências sobre os efeitos da dinâmica micro (particularmente no que diz respeito aos domicílios rurais) sobre o desmatamento regional.

Nesse sentido, a combinação de informações da Figura 2 com aquelas sobre desmatamento em fincas em 1986 e 1996 (Figura 3) permitiria a observação de padrões ou variações intraparroquiais no tempo e, conseqüentemente, uma melhor inferência a respeito do processo de desmatamento. Por exemplo, a análise da Figura 3 pode indicar que uma proporção pequena de fincas localizada ao longo de uma estrada principal, aberta entre 1986 e 1996, responde pela maior

FIGURA 2

Taxas anuais de desmatamento (em \%), segundo parroquias

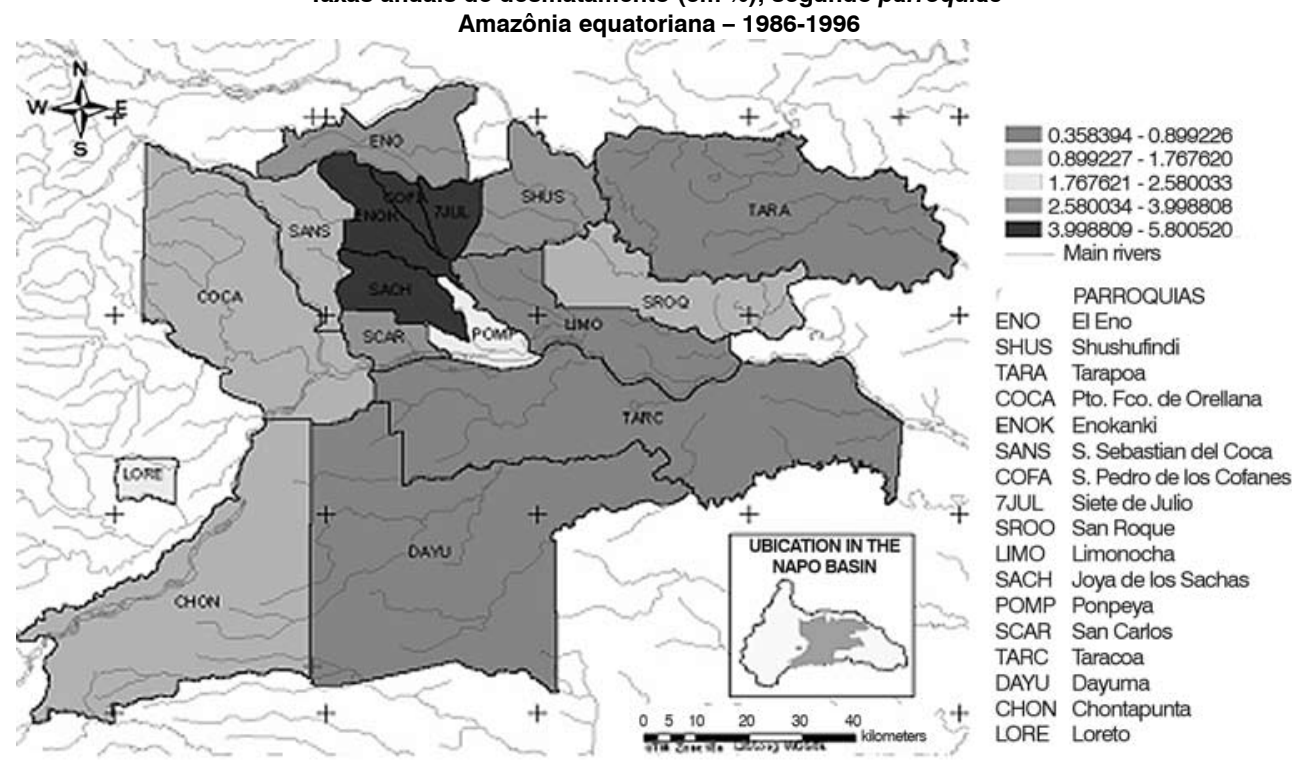

Fonte: Barbieri et al. (2003). 
FIGURA 3

Taxas anuais de desmatamento, segundo fincas Amazônia equatoriana - 1986-1996
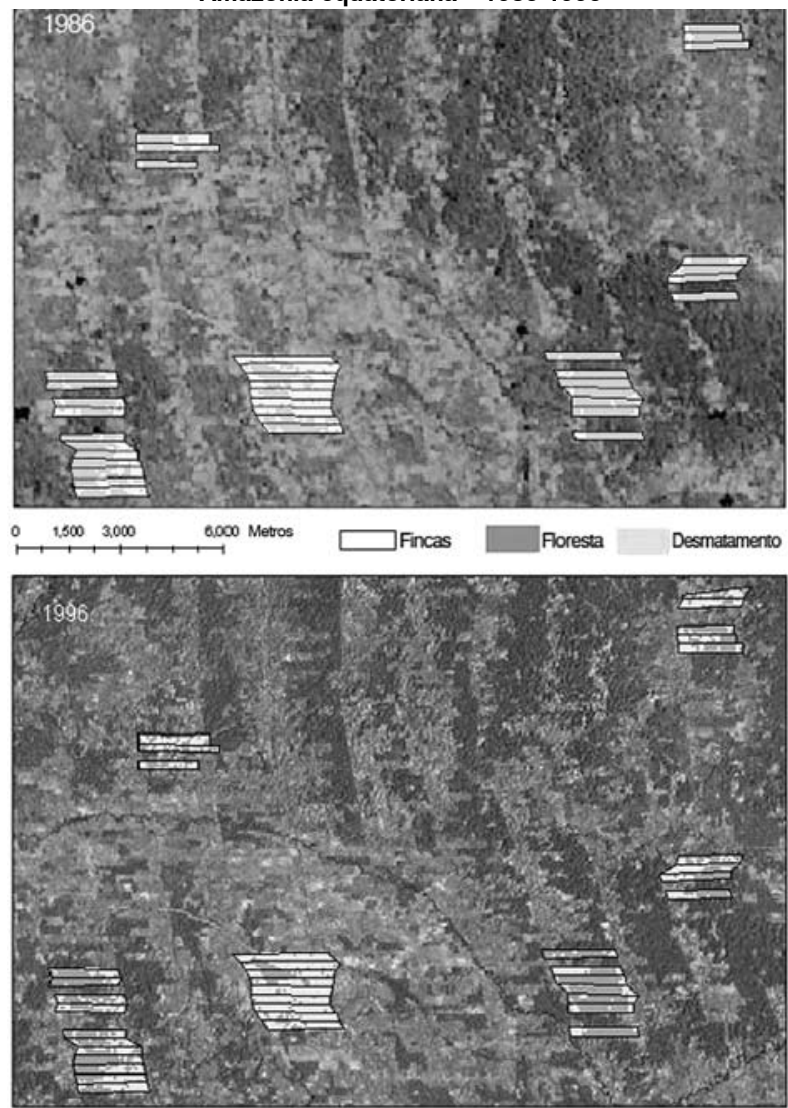

Fonte: Barbieri et al. (2003).

parte do desmatamento em uma parroquia com alta taxa de desmatamento, sugerindo, dessa forma, um estudo mais aprofundado da relação entre acessibilidade física e menores custos de transporte sobre a mobilidade populacional e o desmatamento.

\section{Fontes de dados}

A partir da integração de diferentes escalas e níveis de análise, pode-se desvendar como processos micro (ou macro) repercutem em processos macro (ou micro) na determinação de uma relação específica entre mobilidade populacional, meio ambiente e uso da terra, e modelar, a partir de metodologias adequadas (modelos estatísticos, modelos do tipo agent-based e cellular automata, etc.), as relações entre fenômenos populacionais e características espaciais e ambientais. No caso do exemplo empírico descrito nessa seção, são utilizados dados de pesquisas amostrais realizadas para indivíduos, domicílios e comunidades, bem como sistemas de informação geográfica (SIG) que permitem a análise de atributos espaciais em escalas e níveis tão desagregados quanto a área ocupada por um domicílio rural. Além disso, a disponibilidade de dados longitudinais obtidos de pesquisas amostrais e de imagens de sensoriamento remoto classificadas e integradas a um SIG permite a incorporação de uma escala de análise temporal que aumenta substancialmente o poder explicativo da relação dinâmica entre mobilidade populacional, uso da terra e meio ambiente. 
Os dados mencionados anteriormente referem-se a uma amostra multiestágio de 418 fincas (fazendas), cada uma associada a um domicílio rural. Uma segunda pesquisa realizada em 1999 envolveu a mesma área em estudo e fincas investigadas em 1990, permitindo assim a formação de um banco de dados longitudinal, com informações sobre indivíduos, domicílios rurais e fincas. As coortes mais antigas no banco de dados longitudinal são aquelas em que o chefe de domicílio investigado em 1990 é o mesmo em 1999. As coortes mais jovens são caracterizadas como aquelas em que o domicílio rural foi constituído após 1990 e investigado em 1999, podendo ser de dois tipos: a) no caso de parte da finca ter sido subdividida após a pesquisa em 1990 e estar sendo ocupada por um membro do domicílio investigado em 1990 (por exemplo, o filho do chefe de um domicílio habitado por uma coorte antiga, que se casa e recebe um lote de terra do pai); e b) se parte da terra subdivida foi vendida ou fornecida para terceiros (não relacionados por parentesco ao chefe do domicílio da coorte antiga).

Assim, a pesquisa de campo em 1999 investigou, em função do processo de subdivisão de terras, 767 domicílios rurais associados a 767 fincas gerenciadas independentemente. Além disso, uma nova pesquisa realizada em 2000 (a qual também incluiu a coleta de informações retrospectivas para 1990) permitiu a coleta de informações sobre as 61 comunidades rurais e urbanas de referência para os domicílios rurais nas pesquisas de 1990 e 1999. Todos esses dados foram integrados a um SIG que inclui informações espaciais (como redes de transporte e hidrografia) e evolução de desmatamento e de uso da terra obtidas a partir de classificação de imagens de satélite.

\section{Metodologia}

Barbieri (2006) propõe dois modelos estatísticos multiescalares para investigar os determinantes de dois tipos de mobilidade populacional na Amazônia equatoriana. O primeiro, baseado na equação (1) descrita anteriormente, trata dos determinantes da mobilidade temporária motivada pela busca de emprego (mobilidade realizada nos últimos 12 meses anteriores à pesquisa de campo em 1999, e que não implica mudança permanente de residência). $O$ segundo modelo, que utiliza uma variante da equação (1) incluindo a dimensão temporal, trata dos determinantes da migração (mudança permanente de residência entre 1990 e 1999). Os dois modelos são elaborados no sentido de se investigarem os efeitos de determinantes da mobilidade temporária em três diferentes níveis de agregação: indivíduos, domicílios rurais e comunidades. No modelo de migração, tais fatores também são mensurados ao longo da escala temporal (a cada ano, entre 1990 e 1999). Em particular, fatores ambientais e de uso da terra testados no modelo incluem: tipo de uso da terra; existência de contaminação ambiental; intensificação agrícola; disponibilidade de recursos (especialmente a quantidade de terra); e qualidade da terra.

O modelo conceitual demonstrado na Figura 4 sugere os efeitos esperados (positivos ou negativos) sobre a mobilidade populacional, de variáveis independentes construídas a partir de uma revisão da literatura empírica (ou, em outras palavras, os sinais mostram a forma de associação entre as variáveis independentes e dependentes). O modelo apresenta dois tipos de efeitos. Primeiro, as setas contínuas representam os efeitos diretos e independentes, sobre a mobilidade populacional, de variáveis em três níveis espaciais - indivíduos, domicílios e comunidades. Segundo, as setas interrompidas indicam que fatores em um nível menor de agregação são influenciados por fatores em níveis mais agregados. Por exemplo, variáveis comunitárias agem através de variáveis individuais e domiciliares; nesse caso, fatores comunitários são "filtrados" para os níveis individual e domiciliar. Pelo fato de indivíduos estarem agrupados (clustered) em domicílios, e os domicílios em comunidades, as informações não são totalmente independentes; dessa forma, o modelo indica a necessidade de se considerarem os efeitos das interações entre variáveis em diferentes níveis e escalas. 
FIGURA 4

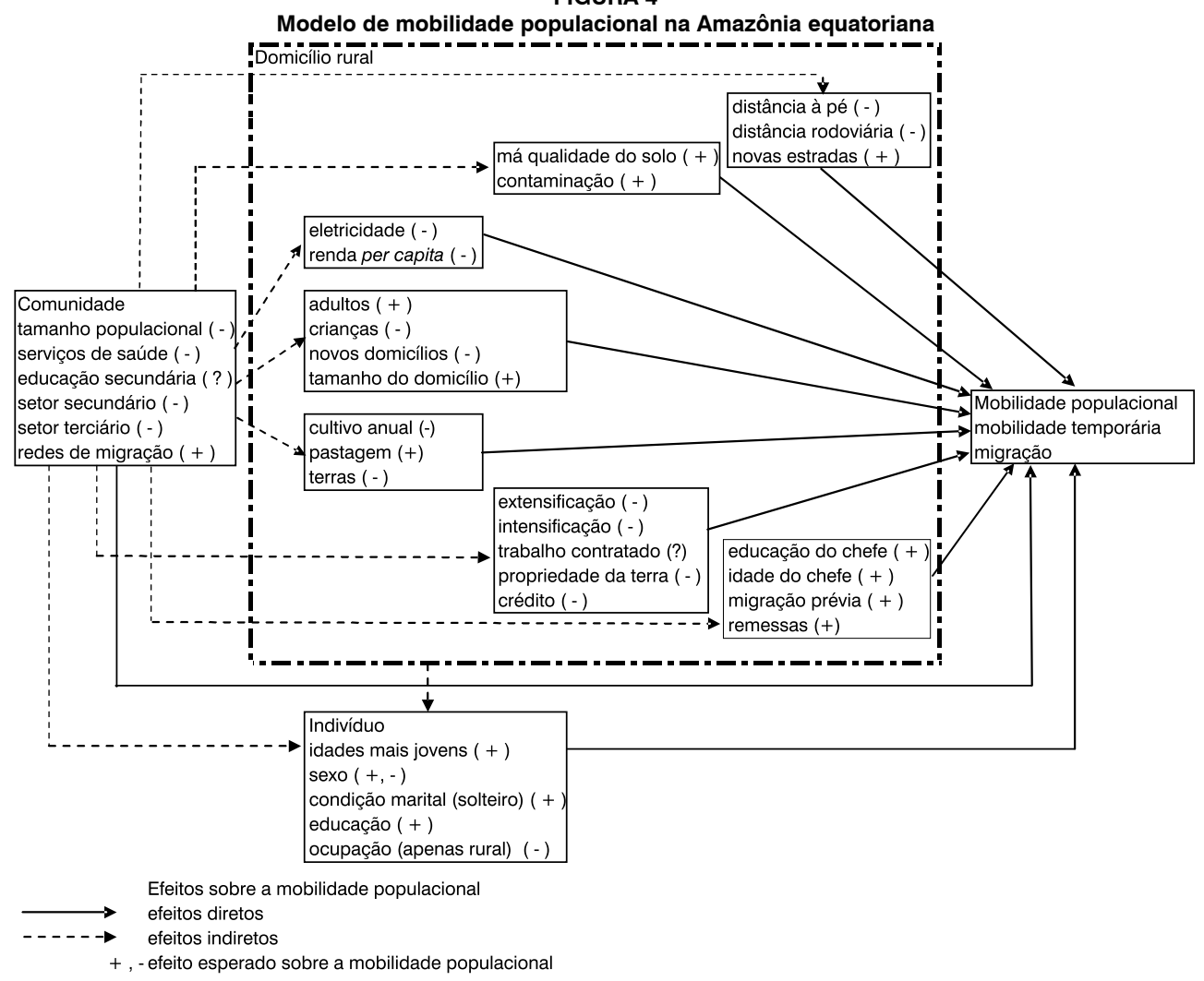

Fonte: Barbieri (2006).

\section{Resultados}

O Quadro 1 traz uma síntese dos principais resultados dos modelos estatísticos multinomiais multiescalares descritos anteriormente. Os modelos testam as variáveis apresentadas na Figura 4, sendo que os resultados estatisticamente significantes $(p<0,10)$ em pelo menos um dos contrastes dos modelos de mobilidade populacional encontram-se no Quadro 1. Os contrastes dos modelos são definidos em relação à decisão de não se mover, e descrevem o lugar de destino do indivíduo que se move-a área de influência da comunidade local, uma outra área rural, ou uma outra área urbana. $O$ Quadro 1 descreve, ainda, como a aplicação dos modelos valida (V) ou contradiz (C) a orientação teórica da litera-tura sobre os determinantes da mobilidade populacional, conforme sugerido na Figura 4, pela relação (positiva ou negativa) entre variáveis inde- pendentes e a mobilidade populacional. Por exemplo, o termo "V+" para a variável "idade jovem" indica que o sinal positivo encontrado na aplicação do modelo valida a relação positiva entre ser um adulto jovem e a mobilidade, enquanto o termo "C-" para "maior educação" indica que a relação negativa entre maior educação e mobilidade contradiz a literatura. Os casos em que o sinal positivo ou negativo é acompanhado de interrogação ("?") são aqueles em que não há concordância, na literatura, sobre a direção da relação entre a variável e a mobilidade.

Seletividade migratória e capital humano

De forma geral, a teoria é robusta para explicar as duas formas de mobilidade como positivamente associadas às idades adultas jovens. No caso de sexo, a falta de uma concordância sobre o efeito na mobilidade pode refletir variações culturais e normativas em diferentes regiões que afetam a sele- 
QUADRO 1

Teste de teorias de mobilidade populacional, por tipo de mobilidade e destino do migrante Amazônia equatoriana - 1990-1999

\begin{tabular}{|c|c|c|c|c|c|c|c|c|}
\hline \multirow{4}{*}{$\begin{array}{c}\text { Orientação teórica } \\
\text { principal }\end{array}$} & \multirow{4}{*}{$\begin{array}{l}\text { Variáveis testadas / } \\
\text { categoria da variável }\end{array}$} & \multicolumn{7}{|c|}{ Validação da orientação teórica por tipo de mobilidade ${ }^{(1)}$} \\
\hline & & \multirow{2}{*}{\multicolumn{3}{|c|}{$\begin{array}{l}\text { Mobilidade } \\
\text { temporária }\end{array}$}} & \multicolumn{4}{|c|}{ Migração } \\
\hline & & & & & Coor & e antiga & $\mathrm{Coc}$ & rte nova \\
\hline & & Local & Urbano & Rural & Rural & Urbano & Rural & Urbano \\
\hline $\begin{array}{l}\text { Seletividade migratória; } \\
\text { capital humano; } \\
\text { Nova Economia da } \\
\text { Migração do Trabalho } \\
\text { (NEMT) }\end{array}$ & $\begin{array}{l}\text { Idade adulta jovem } \\
\text { Maior educação do chefe } \\
\text { Sexo maculino } \\
\text { Maior educação( } \\
\text { Apenas experiência rural } \\
\text { Indivíduo solteiro } \\
\text { I(2) }^{(2)}\end{array}$ & $\begin{array}{l}\text { C- } \\
\text { V- } \\
\text { C- }\end{array}$ & $\begin{array}{l}\mathrm{V}+ \\
\mathrm{V}+? \\
\mathrm{~V}+ \\
\mathrm{C}+\end{array}$ & $\begin{array}{l}\mathrm{V}+ \\
\mathrm{V}+?\end{array}$ & $\mathrm{~V}+$ & $\begin{array}{l}\mathrm{V}+ \\
\mathrm{V}-?\end{array}$ & $\mathrm{~V}+$ & $\begin{array}{l}\mathrm{V}+ \\
\mathrm{V}+ \\
\mathrm{V}-?\end{array}$ \\
\hline $\begin{array}{l}\text { Nova Economia da } \\
\text { Migração do Trabalho } \\
\text { (NEMT) }\end{array}$ & $\begin{array}{l}\text { Usa trabalho assalariado }{ }^{(2)} \\
\text { Usa crédito à produção } \\
\text { Posse da terra }\end{array}$ & $\mathrm{C}+$ & $\begin{array}{l}\mathrm{V}+? \\
\mathrm{C}+\end{array}$ & $\mathrm{C}+$ & & & $\mathrm{C}+$ & $\mathrm{C}+$ \\
\hline $\begin{array}{l}\text { Distância/barreira física } \\
\text { e meio ambiente como } \\
\text { fatores de expulsão }\end{array}$ & $\begin{array}{l}\text { Maior distância à cidade } \\
\text { Maior caminhada à estrada } \\
\text { Há poluição ambiental }^{(2)}\end{array}$ & $\begin{array}{l}V- \\
V- \\
V+\end{array}$ & V- & $\begin{array}{l}\mathrm{V}- \\
\mathrm{V}+\end{array}$ & V- & V- & V- & V- \\
\hline $\begin{array}{l}\text { Ciclo de vida domiciliar; } \\
\text { Teoria das Respostas } \\
\text { Multifásicas (tamanho } \\
\text { do domicílio e da terra) }\end{array}$ & $\begin{array}{l}\text { Maior número de adultos } \\
\text { Maior número de crianças } \\
\text { Chefe mais velho } \\
\text { Mais terra em cultivo } \\
\text { Mais terra em pastagem } \\
\text { Mais terra (hectares) }\end{array}$ & $\begin{array}{l}\mathrm{V}+ \\
\mathrm{C}+ \\
\mathrm{C}- \\
\mathrm{C}- \\
\mathrm{V}-\end{array}$ & $\begin{array}{l}\mathrm{C}+ \\
\mathrm{C}- \\
\mathrm{V}- \\
\mathrm{V}-\end{array}$ & $\begin{array}{l}\mathrm{C}+ \\
\mathrm{C}- \\
\mathrm{V}-\end{array}$ & V- & $\begin{array}{l}\mathrm{V}- \\
\mathrm{V}+ \\
\mathrm{V}+ \\
\mathrm{V}-\end{array}$ & $\mathrm{V}+$ & $\begin{array}{l}V+ \\
V- \\
V+ \\
V- \\
C- \\
C+\end{array}$ \\
\hline $\begin{array}{l}\text { Teoria das Respostas } \\
\text { Multifásicas }\end{array}$ & Intensificação agrícola ${ }^{(2)}$ & V- & V- & & & & & \\
\hline $\begin{array}{l}\text { Teoria do Capital Social } \\
\text { (redes de migração) }\end{array}$ & $\begin{array}{l}\text { Domicílio com emigrante } \\
\text { Educação secundária }\end{array}$ & & & & $\begin{array}{l}\mathrm{V}+ \\
\mathrm{V}-?\end{array}$ & $\mathrm{~V}+$ & $\begin{array}{l}\mathrm{V}+ \\
\mathrm{V}-?\end{array}$ & \\
\hline $\begin{array}{l}\text { Abordagens macro / } \\
\text { estruturalistas }\end{array}$ & $\begin{array}{l}\text { Maior comunidade }{ }^{(2)} \\
\text { Maior setor secundário } \\
\text { Maior setor terciário }\end{array}$ & V- & $\begin{array}{l}\mathrm{V}- \\
\mathrm{C}+\end{array}$ & $\begin{array}{l}\mathrm{V}- \\
\mathrm{V}- \\
\mathrm{C}+\end{array}$ & $\mathrm{C}+$ & V- & $\mathrm{C}+$ & \\
\hline
\end{tabular}

Fonte: Baseado em vários modelos estatísticos em Barbieri (2006).

(1) Considerando: $\mathrm{V}=$ resultado de acordo com a teoria (mesmo sinal); $\mathrm{C}=$ resultado contrário ao esperado pela teoria (sinal contrário); em branco = resultado sem significância estatística ou não testado.

(2) Testado apenas para o modelo de mobilidade temporária.

(3) Testado apenas para o modelo de migração. Os principais resultados são discutidos a seguir, conforme a orientação teórica principal.

tividade da migração. Há uma associação negativa apenas entre ser homem e migrar para uma área urbana. Este resultado pode ser explicado, ao menos em parte, pelo forte viés feminino nesse tipo de mobilidade em áreas de fronteira (BARBIERI; CARR, 2005). Já no caso da mobilidade temporária a associação é positiva. Há uma validação da teoria no que se refere à relação positiva entre maior educação e mobilidade temporária para áreas urbanas, enquanto tal relação é negativa para a mobilidade temporária local. O nível educacional do chefe do domicílio - proxy do nível geral de capital humano do domicílio - gera impacto positivo sobre a migração apenas para áreas urbanas, validando a teoria. Por fim, e ao contrário do sugerido pela literatura, indivíduos solteiros são menos prováveis de se engajarem em mobilidade temporária na comunidade local.

Nova Economia da Migração do Trabalho (NEMT)

Os resultados indicam, ao contrário do esperado, que o acesso ao crédito à produção é um fator de incentivo à mobilidade temporária na comunidade local e em outras áreas rurais, provavelmente indicando uma estratégia domiciliar para amortizar ou pagar dívidas contraídas. Também contrário à expectativa, a segurança fundiária facilita a emigração entre coortes mais novas de colonos e a mobilidade temporária com destino urbano. Nesse caso, a posse legal de título da terra pode estar atuando no sentido de relaxar a necessidade 
de manutenção de força de trabalho na finca. Finalmente, o efeito positivo da contratação de trabalho assalariado sobre a mobilidade temporária pode indicar um processo de substituição de trabalho domiciliar, especialmente aquele direcionado às áreas urbanas (sobretudo o feminino) onde a remuneração tende a ser maior.

\section{Fatores de expulsão}

Conforme esperado, quanto maior a distância a pé do domicílio rural à estrada mais próxima, menores as chances de mobilidade temporária, principalmente dentro da comunidade e em direção às áreas urbanas. Em particular, o efeito sobre o destino urbano pode estar associado ao fato de as mulheres, que possivelmente apresentam maiores dificuldades de deslocamento a longa distância, serem proporcionalmente mais propensas a se deslocarem para áreas urbanas em comparação a outros destinos. Esta associação negativa também é encontrada no caso da migração rural-rural. Conforme esperado, os resultados indicam que, quanto maior a distância rodoviária até uma das quatro principais cidades da região (Lago Agrio, Coca, Shushufindi ou La Joya), menores são as chances de migração (exceto no caso de destino rural para as coortes mais antigas) e de mobilidade temporária com destinos local e rural, possivelmente devido às maiores dificuldades de interação (transporte e comunicação) entre lugares de origem e destino.

Por fim, há uma validação da hipótese de que a presença de contaminação ambiental na finca engendra mobilidade temporária dentro da área de influência da comunidade ou para outras áreas rurais, sendo, portanto, um fator indutor da busca por fontes suplementares de renda em função da queda da produtividade agrícola.

Ciclos de vida domiciliares e teoria das respostas multifásicas

Os resultados validam a hipótese, no caso da migração para coortes novas e da mobilidade temporária local, de que a migração é estimulada quando o domicílio apresenta um número grande de indivíduos adultos.
Uma quantidade elevada de crianças arrefece a migração rural-urbana para os dois tipos de domicílios, provavelmente refletindo o fato de que uma maior presença de crianças tende a maximizar o trabalho adulto, ou mesmo refletindo os efeitos da divisão sexual do trabalho em áreas tradicionais (a mulher permanecendo no domicílio rural e assumindo a tarefa de cuidado dos filhos, em vez de se deslocar para outras áreas). Por outro lado, uma criança adicional vivendo no domicílio tende a aumentar as chances de mobilidade temporária para a comunidade local ou áreas urbanas, provavelmente em função da maior necessidade de renda suplementar para manutenção de um maior número de dependentes, e também como forma de manter, através do vínculo de residência, um maior contato com a família.

Indivíduos pertencentes a domicílios em um estágio mais avançado do ciclo de vida - mensurado pela idade do chefe do domicílio - possuem chance significativa de se engajarem em migração rural-urbana. Chefes mais velhos podem ter acumulado capital e conhecimento ao longo dos anos para investirem em formas menos intensivas de trabalho na produção rural, o que facilita a migração rural-urbana. Esse resultado pode refletir também a maior probabilidade de migração de um membro do domićlio que transita em algum estágio do ciclo de vida individual (especialmente da adolescência para a idade adulta). No entanto, e contrário à expectativa, quanto mais avançada a posição no ciclo de vida domiciliar, menores são as chances de mobilidade temporária.

Uma maior quantidade de terras em cultivos anuais e perenes é associada a menores chances de mobilidade temporária e migração para destinos rurais e urbanos, o que é esperado tendo em vista a relativamente alta demanda por trabalho nestas atividades. Uma maior quantidade de terras em pastagem está positivamente associada a maiores chances de migração rural-urbana para coortes mais antigas (o que poderia indicar uma estratégia de investimento em gado na região, através de remessas de migrantes, conforme sugerido em Barbieri et al., 2006) e, ao contrário do esperado, à decrescente mobilidade temporária local e 
migração rural-urbana para coortes mais novas, nesse último caso provavelmente em função do menor número de produtores em relação a consumidores (crianças) quando comparado às coortes mais antigas.

As chances de migração rural-urbana tendem a ser maiores à medida que aumenta o tamanho das fincas pertencentes às gerações mais novas (ao contrário do esperado), sendo esta relação negativa no caso da migração das coortes antigas e da mobilidade temporária local e urbana (conforme esperado). Por fim, e conforme esperado, investimentos em intensificação agrícola (principalmente por meio do uso de insumos químicos) provavelmente aumentam os retornos ao trabalho, relaxando a necessidade de mobilidade temporária como fonte suplementar de renda.

\section{Capital social}

Redes de migração constituem um importante fator determinante da migração, tendo em vista a redução dos custos de do deslocamento em função do suporte social e econômico e de informação sobre os locais de destino. A exceção é o fluxo rural-urbano em coortes novas, o que é esperado devido ao menor tempo de vida do domicílio, o que diminui a probabilidade de um membro ter migrado em anos anteriores. A presença de escola secundária na comunidade, um indicativo de melhor qualidade de vida e possibilidade de ampliação do capital social, constitui um fator de redução da migração rural-rural nas duas coortes.

\section{Abordagens estruturalistas}

Quanto maior a população da comunidade, menores são as chances de mobilidade temporária, conforme esperado. Comunidades maiores provêm acesso a determinados tipos de serviços e infra-estrutura que melhoram as condições de vida e emprego, podendo assim diminuir a propensão à mobilidade. Uma maior proporção da força de trabalho no setor secundário da economia tem um efeito negativo sobre a migração rural-urbana para coortes mais antigas, atuando, conseqüentemente, na retenção de população, conforme esperado. O efeito também é negativo no caso da mobilidade temporária com destino rural. Já um aumento da proporção da força de trabalho no setor terciário tem impacto positivo (ao contrário do esperado) apenas para migrantes do tipo rural-rural, tanto para coortes antigas quanto para novas. É provável, à medida que as comunidades diversificam seus mercados locais com o aumento do setor terciário em relação ao secundário, que aqueles indivíduos cuja preferência é pelo trabalho rural irão mover-se a despeito das maiores oportunidades no setor terciário (o qual usualmente apresenta, em áreas de fronteira, baixas diversificação e atratividade). Os resultados para a mobilidade temporária também sugerem um efeito positivo de um maior setor terciário sobre a mobilidade temporária com destino urbano ou rural.

\section{Implicações para políticas públicas}

Os resultados sugerem importantes implicações para o planejamento e as políticas públicas que tratam da relação entre mobilidade populacional, uso da terra e meio ambiente. Verificou-se a importância de fatores relacionados ao ciclo de vida domiciliar e de uso da terra na determinação da dinâmica demográfica regional (particularmente no que se refere à mobilidade de indivíduos mais jovens), bem como sua relação com uma pressão populacional latente sobre os recursos naturais da região (e a degradação resultante destes recursos), que engendra mobilidade ruralrural, com a expansão do "ciclo vicioso do desmatamento", e a mobilidade rural-urbana que exerce uma pressão cada vez maior sobre a infra-estrutura urbana.

Em particular, a migração está fortemente associada à maturação de certas características pessoais e domiciliares ao longo do tempo, assim como aos ciclos de uso da terra, ao fortalecimento das redes de migração no tempo e aos processos estruturais relacionados a estratégias de desenvolvimento rural. Por outro lado, a mobilidade temporária envolve estratégias de curto prazo motivadas pelo desejo de diversificação de risco e aquisição de renda para investimento na produção agrícola ou no consumo domiciliar, pela diminuição da produtividade agrícola em função da contaminação am- 
biental (especialmente por petróleo) e por características pessoais e domiciliares que afetam a seletividade da migração.

É importante, também, compreender o papel do momentum populacional, que resulta da alta fecundidade passada e presente, sobre a relação de dependentes e não dependentes na população e sobre a futura oferta de trabalho e demanda de consumo de recursos naturais em áreas rurais. Além desses aspectos, a análise para a Amazônia equatoriana também revela a existência de um momentum na própria dinâmica migratória, devido à formação de redes de migração seguindo uma história de mobilidade envolvendo os domicílios e suas respectivas comunidades.

O modelo representado na Figura 4 e os resultados do Quadro 1 sugerem um conjunto comum de variáveis independentes afetando migração e mobilidade temporária. Entretanto, isso pode ocultar distinções importantes entre os dois tipos de mobilidade. Por exemplo, Brown et al. (1988) sugerem que, enquanto fatores individuais têm um efeito similar tanto sobre a emigração quanto sobre a mobilidade temporária no Equador, suas intensidades variam pelo fato da última estar mais associada com ambientes tradicionais (fatores culturais ou étnicos), enquanto a emigração está mais relacionada à difusão de valores contemporâneos (sistemas modernos de produção, oportunidades de assentamento em novas terras, formação de mercados de trabalho urbanos, etc.).

\section{Conclusão}

A abordagem multiescalar discutida nesse artigo constitui uma proposta analítica da complexa relação de causalidade entre mobilidade populacional, meio ambiente e uso da terra. Nessa perspectiva, a compreensão dos impactos da mobilidade populacional sobre o meio ambiente, e vice-versa, em áreas de fronteira, requer necessariamente a compreensão de contingências espaciais e temporais e efeitos populacionais mediados por fatores políticos, econômicos e ecológicos, conforme sugerido por Carr, Sutel e Barbieri (2006).

A compreensão adequada da causalidade recíproca entre mobilidade popu- lacional, meio ambiente e uso da terra em áreas de fronteira requer a superação de perspectivas disciplinares, em que um dos principais vieses é a simplificação das dimensões espaciais e temporais envolvidas. O uso de abordagens macro pode apresentar problemas de falácia ecológica, enquanto a inferência de condições ou comportamentos de indivíduos para níveis mais agregados de unidades de análise tende a gerar falácia individualista. Além disso, existem unidades sociais além de atores individuais e macro unidades que exercem uma influência significativa em padrões de movimentos humanos. Tais atores podem ser, por exemplo, o domicílio, ou uma unidade de análise caracterizada por determinadas características indutoras de mobilidade (por exemplo, uma comunidade situada em área de risco ambiental).

O exemplo empírico de uma abordagem multiescalar na Amazônia equatoriana sugere que, na ausência de políticas que favoreçam sistemas produtivos rurais (ou, em algumas circunstâncias, mesmo na presença delas), especialmente em relação à absorção de mão-de-obra endógena, a mobilidade populacional torna-se uma alternativa atraente para famílias rurais em áreas de fronteira.

Fatores relacionados à dinâmica dos ciclos de vida domiciliar e de uso da terra e à produtividade agrícola (incluindo oferta e qualidade de terras agriculturáveis e degradação de recursos naturais) interagem com outras características individuais, domiciliares e comunitárias para determinar uma relação específica de causalidade entre mobilidade populacional, meio ambiente e uso da terra. A mobilidade populacional também tem gerado importantes conseqüências ambientais quando dirigidas predominantemente para ecossistemas frágeis, de terras marginais e pouco férteis, as quais se tornam acessíveis através da abertura ou melhoria na rede viária. No sentido inverso, as mudanças no ambiente trazem importantes conseqüências para as populações humanas, sobretudo em termos do comprometimento da sustentabilidade das atividades econômicas.

Entretanto, um maior número de pesquisas empíricas é necessário para clarificar 
relações causais entre estratégias de sobrevivência rurais que envolvem a mobilidade $e$ o desmatamento e degradação de recursos naturais. Faz-se necessário, em particular, discutir como os resultados de uma abordagem multiescalar podem informar os responsáveis pela formulação de políticas públicas a respei-

\section{Referências bibliográficas}

BARBIERI, A.F.; BILSBORROW, R. E.; PAN, W.K. Farm household lifecycles and land use in the ecuadorian Amazon. Population and Environment, New York, v. 27, n. 1, p. 1-27, 2005.

BARBIERI, A. F. People, land, and context: multi-scale dimensions of population mobility in the ecuadorian Amazon. Ann Arbor, Michigan: ProQuest / UMI, 2006.

BARBIERI, A.F.; CARR, D.L. Gender-specific out-migration, deforestation and urbanization in the ecuadorian Amazon. Global and Planetary Change, Amsterdam, v. 47, n.3-4, p. 99-110, 2005.

BARBIERI, A. F.; SAWYER, D.O.; SOARES FILHO, B.S. Population and land use effects on malaria prevalence in the southern brazilian Amazon. Human Ecology, New York, v. 33, n. 6, p. 847-874, 2005.

BARBIERI, A.F.; MENA, C.F.; ERLIEN, C.; BILSBORROW, R.E.; TORRES-NAVARRETE, $B$. Settler welfare and land use in the ecuadorian Amazon. In: OPEN MEETING OF THE HUMAN DIMENSIONS OF GLOBAL ENVIRONMENTAL CHANGE RESEARCH COMMUNITY. Montreal, Canada, October 16-18, 2003.

BARBIERI, A. F. Uso da terra e prevalência de malária em uma região da Amazônia brasileira. Caderno de Geografia, Belo Horizonte, v. 15, n. 24, p. 9-30, 2005.

BETTREL, C. B.; HOLLIFIELD, J. F. Migration theory. In: BETTREL, C. B.; HOLLIFIELD, J. F. (Orgs.). Migration theory: talking across disciplines. New York: Routledge, 2000.

BILSBORROW, R.E.; BARBIERI, A.F.; NAVARRETE, B.T. Changes in population and land use over time in the ecuadorian Amazon. Acta Amazonica, v. 34, n.4, p.635-647, 2004. to das conseqüências da mobilidade populacional sobre a urbanização, o desmatamento e o desenvolvimento regional e, em um sentido inverso, como desmatamento e urbanização são fatores que, por si só, fomentam mais mobilidade no tempo, em um processo de causalidade cumulativa.

BILSBORROW, R.E.; CARR, D.L. Population, agricultural land use and the environment in developing countries. In: LEE, D.R.; BARRET, C.B. (Orgs.). Tradeoffs or synergies? Agricultural intensification, economic development and the environment. New York: CABI Publishing, 2001, p. 35-55.

BILSBORROW, R. E.; McDEVIT, T.M.; KOSSOUDJI, S.; FULLER, R. The impact of origin community characteristics on rural-urban out-migration in a developing country. Demography, v. 24 , n.2, p. 191210, 1987.

BILSBORROW, R. E.; OBERAI, A. S.; STANDING, G. Migration surveys in low income countries: guidelines for survey and questionnaire design. London and Sydney: Croom Helm, 1984.

BLAIKIE, P.; BROOKFIELD, H. Land degradation and society. London and New York: Methuen, 1987.

BROWDER, J. O.; GODFREY, J.O. Rainforest cities: urbanization, development and globalization of the brazilian Amazon. New York, Columbia University Press, 1997.

BROWN, L. A.; BREA, J.L.; GOETZ, A.R. Policy aspects of development and individual mobility: migration and circulation from Ecuador's rural Sierra. Economic Geography, v. 64, n.3, p. 255-278, 1988.

CURRAN, S. Migration, social capital, and the environment: considering migrant selectivity and networks in relation to coastal systems. Population and Development Review, New York, v. 28 (Supplement), p. 89-125, 2002.

DAVIS, $K$. The theory of change and response in modern demographic history. Population Index, v. 29, n.4, p. 345-366, 1963. 
GIBSON, C. C.; OSTROM, E.; AHN, T.K. The concept of scale and the human dimensions of global change: a survey. Ecological Economics, v.32, n.2, p. 217-239, 2000.

HARBISON, S. F. Family structure and family strategy in migration decision making. In: DE JONG, G.; GARDNER, R. W. Migration decision making: multidisciplinary approaches to microlevel studies in developed and developing countries. New York: Pergamon Press, 1981.

LIPTON, M. Why poor people stay poor: a study of urban bias in development. London: Temple Smith, 1977.

MARQUETE, C. M. Land use patterns among small farmer settlers in the northeastern ecuadorian Amazon. Human Ecology, New York, v. 26, n. 4, p.573-598, 1998.

MASSEY, D. Social structure, household strategies, and the cumulative causation of migration. Population Index, v. 56, n.1, p. 3-26, 1990.

MCCRACKEN, S. D.; SIQUEIRA, A.; MORAN, E.F.; BRONDIZIO, E. Land use patterns on an agricultural frontier: insights and examples from a demographic perspective. In: WOOD, C.H.; PORRO, R. Deforestation and land use in the Amazon. Gainesville, Florida: University Press of Florida, 2002, p.162-192.

MYRDAL, G. Rich lands and poor lands. New York: Harper and Row, 1957.

PAN, W. K.; BILSBORROW, R. E. The use of a multilevel statistical model to analyze factors influencing land use: a study of the ecuadorian Amazon. Global and Planetary Change, v. 47, n. 2-4, p. 232-252, 2005.

PIORE, M. Birds of passage: migrant labor in industrial societies. Cambridge: Cambridge University Press, 1979.

RHODA, R. Rural development and urban migration: can we keep them down on the farm? International Migration Review, New York, v.17, n.1, p. 34-64, 1983.

SAWYER, D. R. Fluxo e refluxo da fronteira agrícola no Brasil: ensaio de interpretação estrutural e espacial. Revista Brasileira de Estudos Populacionais, v. 1, n.1/2, p.3-34, 1984.
SIMON, H. Administrative behavior. New York, Free Press, 1976.

STARK, O.; LEVHARI, D. On migration and risk in LDCs. Economic Development \& Cultural Change, p. 191-196, 1982.

STILWELL, J.; CONGDON, P. Migration modelling: concepts and contents. In: STILWELL, J.; CONGDON, P. Migration models: macro and micro approaches. London and New York: Belhaven Press, 1991, p. 1-16.

THORNER, D.; KERBLAY, B.; SMITH, R.F. A.V. Chayanov on the theory of peasant economy. Madison: University of Winsconsin Press, 1986.

VANWEY, L. K.; D’ANTONA, A.; BRONDÍZIO, E.; MORÁN, E. Uso da terra, ciclo da unidade doméstica e ciclo de vida do lote na Amazônia brasileira. In: ENCONTRO NACIONAL DA ASSOCIAÇÃO BRASILEIRA DE ESTUDOS POPULACIONAIS - ABEP. Anais... Caxambu, 2006.

WALKER, R.; HOMMA, A. K. Land use and land cover dynamics in the brazilian Amazon: an overview. Ecological Economics, v.18, n.1, p.67-80, 1996.

WALKER, R.; PERZ, S.; CALDAS, M.; TEIXEIRA, L. Land use and land cover change in forest frontiers: the role of household life cycles. International Regional Science Review, v. 25, n.2, p. 169-199, 2002.

WALSH, S. J.; BILSBORROW, R. E.; MCGREGOR, S.J.; FRIZZELLE, B.; MESSINA, J.P.; PAN, W.K.; CREWS-MEYER, K.A.; TAFF, G.N.; BAQUERO, F. Integration of longitudinal surveys, remote sensing time series, and spatial analysis. In: FOX, J.; RINDFUSS, R.R.; WALSH, S.J.; MISHRA, V. People and the environment: approaches for linking household and community surveys to remote sensing and GIS. Boston: Kluwer Academic Publishers, 2003, p.91-130.

WEEKS, R. The role of spatial analysis in demographic research. In: GOODCHILD, $M$. F. Spatially integrated social science. Oxford, UK: Oxford University Press, 2004, p. 381-399. 
WOOD, C.H. Equilibrium and historicalstructural perspectives on migration. International Migration Review, New York, v.16, n.2, Special Issue: Theory and Methods in Migration and Ethnic Research, 1982.
WOOD, C. H. Land use and deforestation in the Amazon. In: WOOD, C.H.; PORRO, R. Deforestation and land use in the Amazon. Gainesville, Florida: University Press of Florida, 2002, p.1-38.

\title{
Resumen
}

Movilidad poblacional, medio ambiente y uso de la tierra en áreas de frontera: un abordaje multiescalar

La movilidad poblacional ha sido históricamente uno de los más importantes determinantes próximos de la deforestación y la degradación de los recursos naturales en áreas de frontera. Los abordajes analíticos "multiescalares" son particularmente apropiados para comprender este tipo de relación entre movilidad poblacional, medio ambiente y uso de la tierra como resultante de la operación de factores en diferentes, aunque interconectadas, escalas y niveles de análisis espaciales y temporales. Sin embargo, ha sido realizada una escasa investigación empírica en la identificación simultánea de factores a distintas escalas y niveles que afectan tal relación. Buena parte de la literatura privilegia el estudio de datos agregados, prestando menor atención al análisis micro (individuos y domicilios) y su evolución en el tiempo. La focalización fue en el impacto sobre los bosques tropicales, y no necesariamente en las condiciones de vida y la movilidad de las familias migratorias que son directamente responsables de gran parte de esos impactos. Este artículo discute aspectos teóricos y metodológicos de un abordaje multiescalar en el estudio de la relación entre movilidad poblacional, medio ambiente y uso de la tierra, además de presentar un ejemplo empírico en un área de colonización agrícola en la Amazonia ecuatoriana.

Palabras-clave: Movilidad poblacional. Medio ambiente. Uso de la tierra. Frontera. Abordaje multiescalar.

\begin{abstract}
Demographic mobility, the environment, and use of the land in border areas: a multi-scale approach
\end{abstract}

Historically, demographic mobility has been one of the most important determinants in areas where there has been deforesting and deterioration of natural resources. "Multi-scale" analytic approaches are especially appropriate for dealing with this type of relationship between demographic mobility, environment and the use of the land as the result of the interaction of factors in different but interconnected scales and levels of spatial and temporal analysis. But little research has been done in identifying concurrent factors on these different scales and at different levels that affect this relationship. Much of the literature gives stronger emphasis to the study of aggregated data and less to micro-analysis (individuals and households and their evolution in time). The focus has been the impact on the tropical forests and not necessarily on the living conditions and mobility of the migrant families who are directly responsible for a high proportion of these impacts. This article presents a discussion on theoretical and methodological aspects of a multi-scale approach to the study of the relationships between demographic mobility, environment, and the use of the land. It also presents an empirical example in an area of agricultural colonization in the equatorial Amazon Basin.

Keywords: Demographic mobility. Environment. Land use. Border. Multi-scale approach. 